\title{
Behaviour of indicators of exposure and effect after cessation of occupational exposure to lead
}

\author{
L Alessio, ${ }^{1}$ M R CASTOLdi, ${ }^{3}$ P ODONE, ${ }^{1}$ AND I FRANCHINI ${ }^{2}$ \\ From Clinica del Lavoro " $L$ Devoto" dell'Università di Milano, ${ }^{1} 20122$ Milan, Cattedra di Medicina del \\ Lavoro dell'Università di Parma, ${ }^{2}$ Parma, and Laboratorio di Ricerche Cliniche ${ }^{3}$ degli Istituti Clinici di \\ Perfezionamento di Milano, Milan, Italy
}

ABSTRACT The behaviour of blood lead $(\mathrm{PbB})$ and of some indicators of effect (erythrocyte protoporphy rin IX (EP), $\delta$-aminolaevulinic acid dehydratase activity of erythrocytes (ALAD), and urinary $\delta$-aminolaevulinic acid (ALAU)) were studied in subjects who had ceased working with inorganic lead for at least one year. Relations between these indices and chelatable lead (Pbu-EDTA (lead in urine after injection of $\mathrm{CaNa}_{2}$ EDTA $1 \mathrm{~g}$ intravenously)), a test that is used to evaluate the lead deposits in the body, were also analysed. As a comparison, a group of subjects currently exposed was studied. In the workers with past exposure the $\mathrm{PbB}$ values were significantly lower, at the same PbU-EDTA levels, than those found in subjects at work. The relation between EP and PbUEDTA shows that, for corresponding levels of chelatable lead, the values of the erythrocyte metabolite are identical in the two groups. Considering the EP-PbB relation, however, at the same PbB levels the protoporphyrin values appear distinctly more altered in the subjects with past exposure. Similar results were obtained from a study of the relations between ALAD and PbU-EDTA and between ALAD and PbB. The relation between ALAU and PbU-EDTA, however, shows that, at the same PbU-EDTA levels, the urinary metabolite in past-exposed subjects is distinctly lower than in subjects at work, while the relation between ALAU and PbB shows that, for similar blood lead values, the ALAU levels are identical. On the basis of the results obtained it is concluded that in subjects with past exposure, EP and ALAD can be used in establishing the persistence and extent of an "active deposit" of lead in the organism, while $\mathrm{PbB}$ is of very limited use.

In working environments where toxic substances are used exposure rarely remains constant over time. Over the years, in fact, with an ever increasing knowledge of health problems, measures have usually been taken to reduce the atmospheric concentrations of toxic substances. A good example of this is inorganic lead. In the 1960s the American Conference of Governmental Industrial Hygienists fixed a maximum allowable atmospheric concentration of $0.2 \mathrm{mg} / \mathrm{m}^{3}$, and $\mathrm{Kehoe}^{1}$ recommended a "permissible" blood lead concentration of $80 \mu \mathrm{g} / 100$ $\mathrm{ml}$. In recent years international bodies and governmental agencies have recommended a TLV-TWA of $0.1 \mathrm{mg} / \mathrm{m}^{3}$ and indicate a permissible blood lead concentration of $60 \mu \mathrm{g} / 100 \mathrm{ml}$ for men and $40 \mu \mathrm{g} / 100$ $\mathrm{ml}$ for women. ${ }^{23}$ As a result of this continual evolution in prevention, many workers who were

Received 27 September 1979

Accepted 13 February 1980 exposed to high lead concentrations in the past are presently exposed to concentrations below the TLV, and biological monitoring shows them to have permissible concentrations of blood lead.

Moreover, in working environments where hygiene conditions are not satisfactory, it is common practice to remove, for varying periods, those subjects with biological indicators exceeding the permissible values. Despite interruption of exposure, high deposits of lead probably remain in the tissues of such workers, and it may be necessary to determine the extent of these deposits before deciding whether they may be re-exposed to lead.

In consideration of the above it appeared important to assess whether subjects who had an "abnormal" exposure to lead may, a considerable time after cessation of exposure, show alterations due to the presence of lead in the tissues. Currently the only means by which the active deposits of lead may be evaluated is by the determination of chelatable 
lead; this test is indicative even when some time has elapsed between termination of exposure and the investigation. 45

In subjects who had ceased lead-exposing work for at least one year we studied the relations between chelatable lead and blood lead, chelatable lead and indicators of effect, and blood lead and indicators of effect.

In the present study we have considered as indicators of biological effect the tests that permit the study of alterations caused by lead on haem synthesis-erythrocyte protoporphyrin concentration (EP), $\delta$-aminolaevulinic acid dehydratase activity (ALAD), and urinary $\delta$-aminolaevulinic acid concentration (ALAU).

\section{Subjects and methods}

The study was made on men aged between 30 and 35 who had ceased inorganic lead-exposing work for a period exceeding 12 months and who had been exposed to the metal for at least four years. The data thus obtained were compared with those from subjects currently occupationally exposed to lead for at least one year. All subjects examined in the study were informed of the purpose of the study and volunteered to participate.

$\mathrm{PbB}, \mathrm{ALAD}$, and EP were analysed on heparinised venous blood. ALAU was determined on samples of urine collected over 24 hours; however, it was preferred to express the values as a concentration since for many subjects the established intervals were not respected. Chelatable lead was determined on urine collected in the 24 hours after administration of $\mathrm{CaNa}_{2}$ EDTA $(1 \mathrm{~g}$ in $250 \mathrm{ml}$ of $5 \%$ glucosate solution).

Lead in blood and in urine was determined by atomic absorption spectrophotometry, using the method of Mitchell et al l $^{6}$ for lead in blood, and the method of Zurlo et al ${ }^{7}$ for lead in urine. ALAD was determined with the European Standardised Method, ${ }^{8}$ EP with the method of Schwartz and Wikoff, ${ }^{9}$ and ALAU with the method of Grisler and Griffini. ${ }^{10}$ Lead in blood determination is under constant control in the CEC (Luxembourg) interlaboratory programme.

The functional relations between the various pairs of tests were examined by means of regression analysis. For each curve examined the significance of the correlation and the significance of the specific parameters of the curve were tested. In addition, when the individual curves were statistically significant, the existence was tested of possible differences in the profile of the regression lines in the two groups of subjects. In practice, we checked whether the slope of the line was the same; when an identical slope was found, a test was carried out to see whether the ordinates at the origin of the two lines were significantly different, to see whether they were parallel or coincidental.

Since it has not been possible to perform all the biological tests in all the subjects examined, the number of points used in the various regression analyses are different.

\section{Results and discussion}

\section{BLOOD LEAD}

In 48 subjects with current exposure to lead, the PbU-EDTA levels were closely correlated with the PbB levels $(r=0.85 ; p<0.001)$; in 45 subjects with past exposure, however, the correlation between the two tests was lower $(r=0.54)$, even though statistically significant $(p<0.001)$. In both cases the regression functions that best fitted the data were linear (fig 1). From the figure it can be seen that there is a distinct difference in trend of the two regression lines: for an identical variation in PbU-EDTA the variations in $\mathrm{PbB}$ are higher in currently exposed subjects. Statistical analysis showed that the trend of the two lines was significantly different $(t=3.63$;

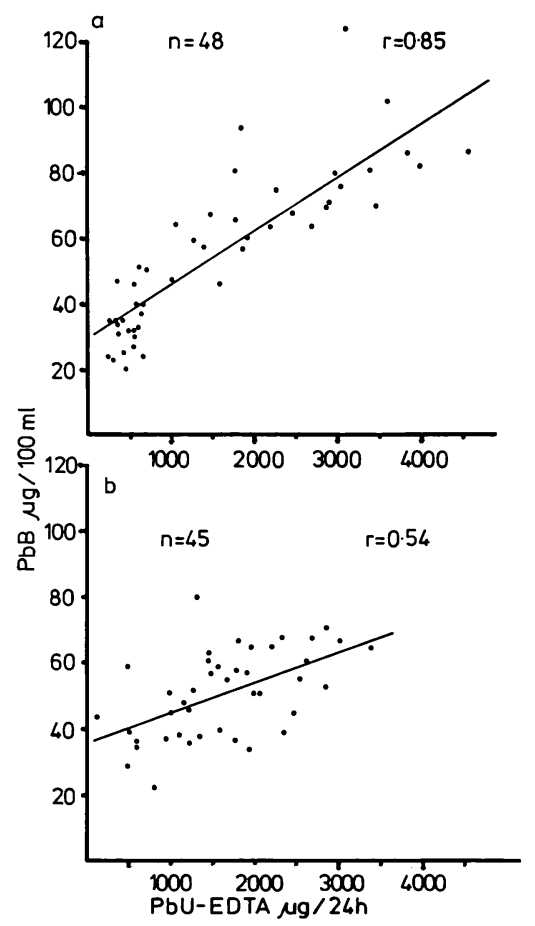

Fig 1 Relations between $P b U-E D T A$ and $P b B$ in (a) currently and (b) past-exposed workers. Linear type regression functions. 
$\mathrm{p}<0.001)$. These data, discussed more extensively in a previous paper, ${ }^{11}$ indicate that $\mathrm{PbB}$ in subjects who have ceased working with lead cannot be reliably used to evaluate indirectly active lead deposits. This test, therefore, cannot be used to establish whether a person may or may not resume work with lead after a period away.

\section{ERYTHROCYTE PROTOPORPHYRIN}

It is well known that EP returns to normal more slowly than other indicators after interruption of exposure and also that in subjects who have been severely exposed protoporphyrin concentrations remain high for many years. In a previous study in a group of subjects who had ceased work with lead for more than one year we confirmed that, for corresponding $\mathrm{PbB}$ levels, the EP concentrations were decidedly higher than those of currently exposed subjects, whereas the regression curves between PbU-EDTA and EP in the two populations were practically identical. ${ }^{12}$

Since the regression curves between EP and both

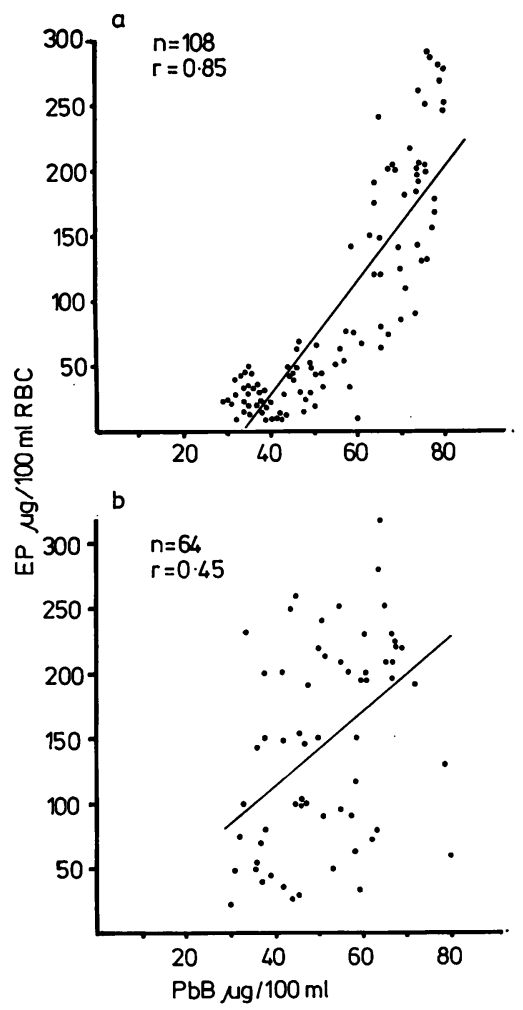

Fig 2 Relations between PbB and EP in (a) currently and (b) past-exposed workers. Linear type regression functions.
$\mathrm{PbB}$ and PbU-EDTA were logistic, a statistical comparison between them would have been extremely complicated. Therefore, we decided to take into account only subjects with $\mathrm{PbB}$ levels in the range $30-80 \mu \mathrm{g} / 100 \mathrm{ml}$ and with PbU-EDTA values in the range $500-3000 \mu \mathrm{g} / 24 \mathrm{~h}$ (figs 2 and 3 ). In this way the statistical comparison between the regression curves in the two populations (currently exposed and pastexposed) was easy: in fact, the regression functions were linear.

In 64 subjects who had ceased work a year before, the correlation coefficient between $\mathrm{PbB}$ and EP was lower $(r=0.45)$ than in 108 currently exposed subjects $(r=0.85 ; p<0.001)$, although still statistically significant $(p<0.001)$. By contrast a study of the relation between EP and chelatable lead showed that the two variables were well correlated both in 48 subjects still at work $(r=0.88 ; p<0.001)$ and in 56 subjects no longer exposed $(r=0.72 ; p<0.001)$.

The comparison made to test any difference in trend of the regression lines between $\mathrm{PbB}$ and EP showed that the slope of the two lines is statistically

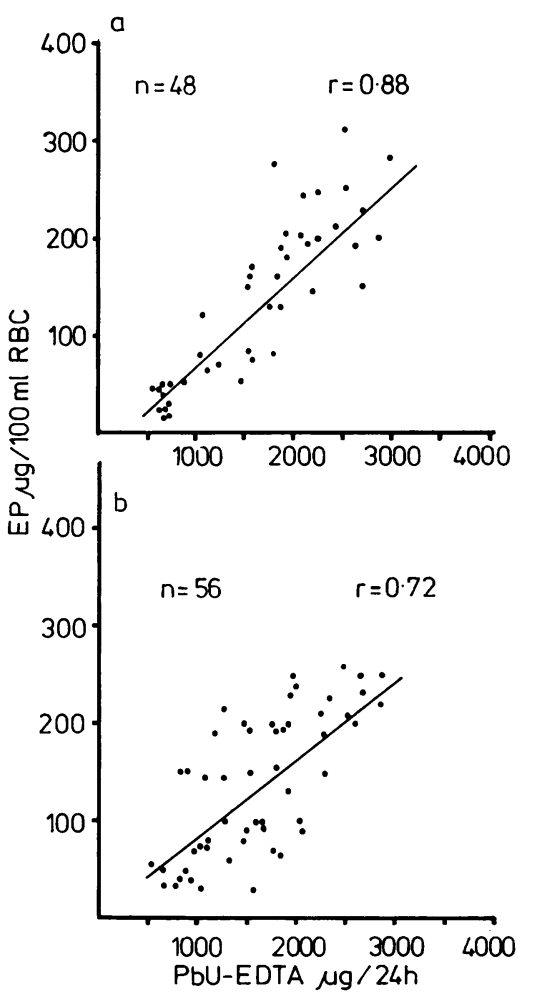

Fig 3 Relations between PbU-EDTA and EP in (a) currently and (b) past-exposed workers. Linear type regression functions. 
different $(\mathrm{t}=2.28 ; 0.02<\mathrm{p}<0.05)$, while the slopes of the regression lines between PbU-EDTA and EP do not differ $(t=0.93 ; p=n s)$; the latter two lines also coincided $(t=0.56 ; p=n s)$.

These data confirm that both chelatable lead and EP remain high for a long time after termination of exposure and suggest that EP stays at high concentrations possibly due to a direct inhibition of haem synthesis by the lead released from the deposits. The disproportionately low blood lead concentrations, considering the effect (high EP) in subjects no longer exposed, could be due to the fact that the quantity of lead that diffuses in the plasma from the deposits is usually small and is therefore not able to influence the blood lead concentrations; on the other hand, the plasma-lead concentration is not a constant function of the total blood lead. ${ }^{13}$

The results obtained show that measurement of EP will be particularly useful for the occupational physician who must decide whether a person who had been exposed to lead in the past may or may not resume a lead-exposing job. In fact, when there is no sideropaenia, high concentrations of the erythrocyte metabolite are evidence of an active lead deposit.

\section{ERYTHROCYTE ALAD}

Tola $^{14}$ and Haeger-Aronsen et al ${ }^{15}$ have shown that in subjects who have been exposed to a "moderate" degree ALAD rises progressively after removal from exposure until "normal" concentrations are reached

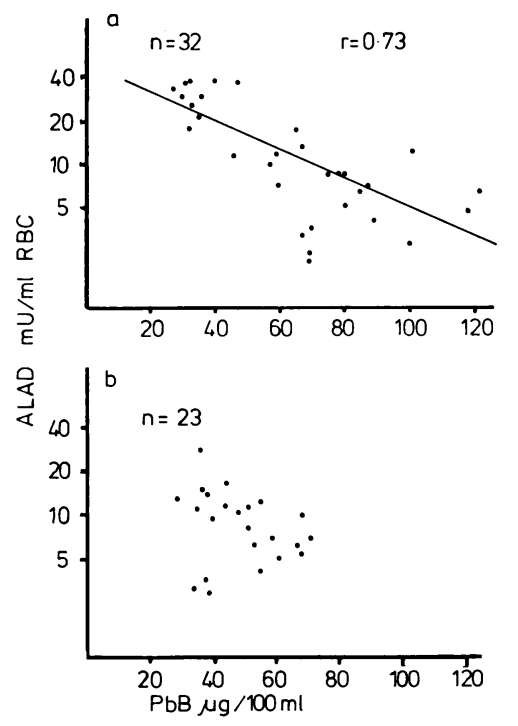

Fig 4 Relations between PbB and ALAD in (a) currently and $(b)$ past-exposed workers. Exponential type regression functions. Logarithmic scale on ordinate. in parallel with the reduction in blood lead concentrations.

In subjects who have been "severely" exposed, however, Bonsignore and Ottenga ${ }^{16}$ found that ALAD remains appreciably inhibited even after chelation therapy, and the inhibition is not proportionate with the $\mathrm{PbB}$ levels; according to these authors a factor other than lead, probably a thermolabile inhibitor, is the cause of the ALAD inhibition.

In 32 currently exposed subjects we found that ALAD was closely correlated both with $\mathrm{PbB}$ and chelatable lead $(r=0.73 ; p<0.001-r=0.70$; $\mathrm{p}<0.001$ respectively). In 23 subjects who had ceased work with lead ALAD and PbB were not significantly correlated $(r=0.22)$, while the correlation coefficient was $r=0.46(p<0.05)$ between ALAD and PbU-EDTA.

The regression curves that best fitted the data were exponential and are represented as a straight line on a semilogarithmic scale (figs 4 and 5).

These results show that in past-exposed subjects no functional relation exists between PbB and ALAD, which contrasts with the findings of $\mathrm{Tola}^{14}$ and Haeger-Aronsen et al. ${ }^{15} \mathrm{~A}$ tentative explanation for this difference could be that the group in our study consisted of subjects with appreciably higher exposures than those of the groups studied by the Scandinavian authors.

A comparison of the two lines showed that the

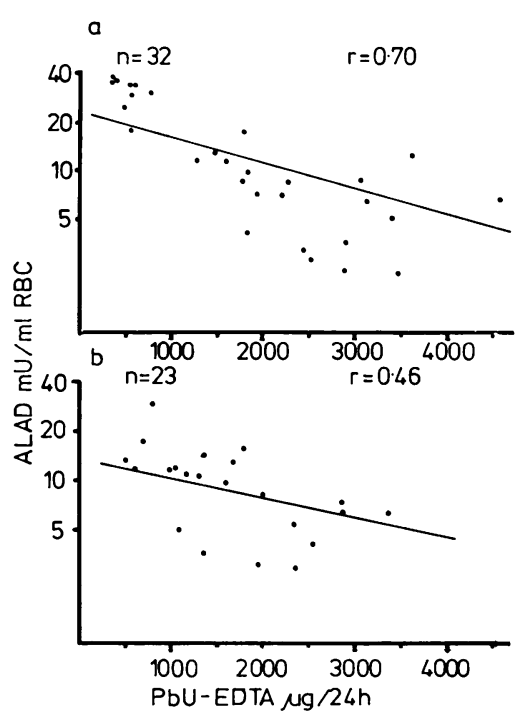

Fig 5 Relations between PbU-EDTA and ALAD in (a) currently and (b) past-exposed workers. Exponential type regression functions. Logarithmic scale on ordinate. 


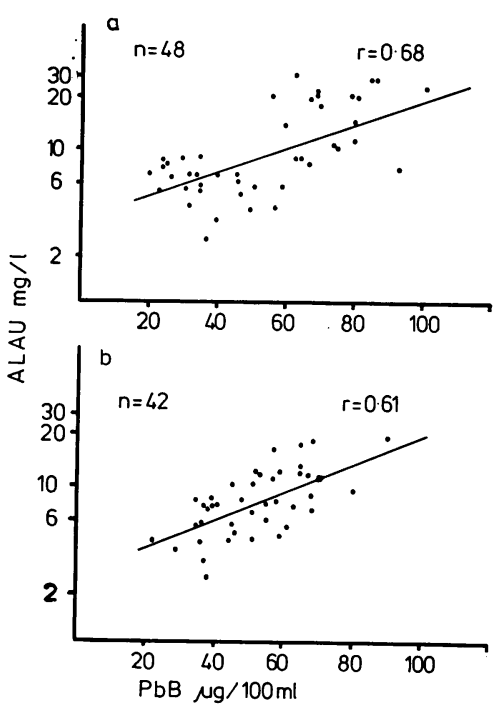

Fig 6 Relations between $P b B$ and $A L A U$ in (a) currently and $(b)$ past-exposed workers. Exponential type regression functions. Logarithmic scale on ordinate.

functional relations between PbU-EDTA and ALAD in the currently exposed and past-exposed subjects do not differ; the slope of the curves was the same $(t=0.77 ; p=n s)$, and from a statistical point of view the curves themselves were coincidental $(\mathrm{t}=1.89 ; \mathrm{p}=\mathrm{ns})$.

The results obtained should be interpreted with considerable caution in view of the fact that the group of subjects under study was small. These data, however, appear to lend validity to the hypothesis already advanced by Prerovska and Teisinger ${ }^{17}$ that in subjects with past exposure to lead, a reduction in erythrocyte ALAD results from the biological effect of the metal that is slowly released from tissue deposits. Furthermore, our data, although not in agreement with the hypothesis of enzymatic inhibition, enable us to conclude, in agreement with Bonsignore, ${ }^{16}$ that measurement of ALAD may be used to disclose the existence of a severe past exposure to lead, when it is necessary, for example, to establish whether a chronic symptomatology is due to a past exposure or whether symptoms of evident intoxication occurring in the past are to be attributed to lead poisoning.

URINARY ALA

It has been shown that after cessation of lead exposure excretion of ALA in the urine diminishes rapidly. 141517 In our study we found that in current exposure and after cessation of exposure there is a

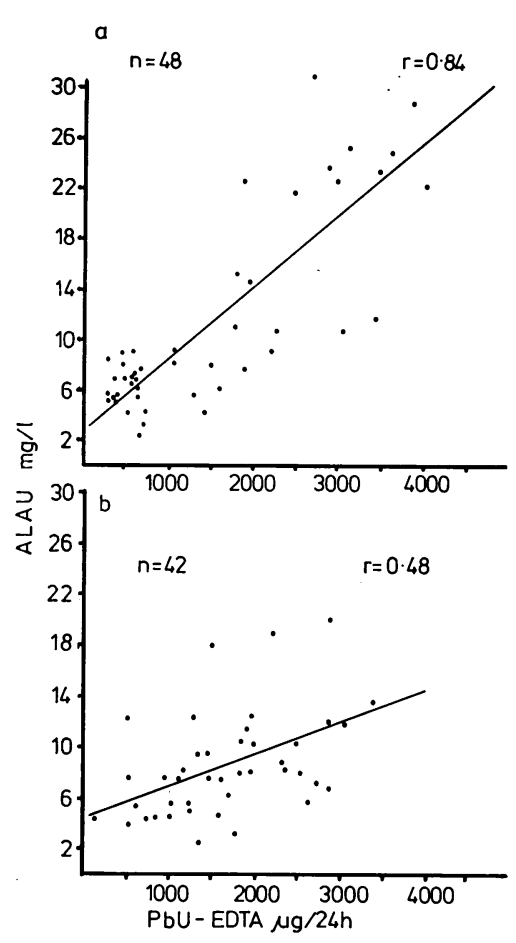

Fig 7 Relations between PbU-EDTA and ALAU in (a) currently and (b) past-exposed workers. Linear type regression functions.

good correlation between PbB and ALAU $(r=0 \cdot 68$, $p<0.001$ and $r=0.61, p<0.001$ respectively). The regression curves were exponential (fig 6). Comparison of the curves showed that variations in ALAU with respect to $\mathrm{PbB}$ do not differ in the two populations; the slope was the same $(t=0.48 ; p=n s)$ and the curves were coincidental $(t=1.40 ; p=n s)$.

The correlation between PbU-EDTA and ALAU was significant in the two groups, even though it was less close in the past exposed $(r=0.84 ; p<0.001$ and $r=0.48 ; p<0.001$ respectively). The regression functions were linear. Comparison between the lines showed that, at the same PbU-EDTA levels, in the past-exposed subjects the ALAU values were decidedly lower than those found in the currently exposed subjects (fig 7). Statistical analysis confirmed that the slopes of the two lines were different $(\mathrm{t}=3.2 ; \mathrm{p}<0.01)$.

The behaviour of ALAU in relation with exposure was identical to that of $\mathrm{PbB}$, so that our results show, in agreement with the authors quoted above, that this test cannot be used after cessation of exposure to establish the amount of active lead deposit in the organism. 


\section{Conclusions}

From the above it is clear that not all tests commonly used for biological monitoring of subjects currently exposed to lead can also be used for the surveillance of subjects who have ceased leadexposing work. Particularly, $\mathrm{PbB}$ is of very limited value in establishing the persistence and degree of an active lead deposit.

As for the indicators of effect, determination of EP and ALAD permits detection of alterations in haem synthesis, caused probably by the lead released from the deposit organs even many years after cessation of work.

These two indicators may therefore be used to identify subjects who have been severely exposed in the past, even when other tests are poorly significant. ALAU, however, is of no use.

The confirmation that subjects who have stopped working with lead can have high metabolically active deposits of lead leads us to believe that the problem raised in the introduction may be real-that is, subjects working at present exposed to "low" lead concentrations but who have been exposed to righer concentrations in the past could have active deposits of the metal such as to cause more pronounced effects than would be expected on the basis of an evaluation of the subsequent exposure.

It is therefore necessary that a similar study also be made in subjects exposed to lead concentrations that are presently considered "acceptable" and who have been exposed to much higher concentrations of the metal in the past.

\section{References}

${ }^{1}$ Kehoe RA.The Harben Lectures. The metabolism of lead in man in health and diseases. Journal of Royal Institute of Public Health and Hygiene 1961 ;24:81-97.

2 Zielhuis RL. Second International Workshop permissible levels for occupational exposure to inorganic lead. Int Arch Occup Environ Health 1977;39:55-9.

${ }^{3}$ National Institute for Occupational Safety and Health. Inorganic lead, revised criteria. Criteria for a recommended standard. Washington: US Department of Health, Education and Welfare, 1978.

- Teisinger J, Prerovska I, Sedivec V, Flek J, Roth Z. Attempt on determination of biologically active lead in organism in experimental poisoning. Int Arch Gewerbepath Gewerbehyg 1969;25:240-55.

${ }^{5}$ Nordberg GF. Effects and dose-response relationship of toxic metals. Amsterdam: Elsevier Scientific Publishing Company, 1976:7-96.

${ }^{8}$ Mitchell DG, Ryan FJ, Aldous KM. The precise determination of lead in whole blood by solvent extractionatomic absorption spectrometry. Atomic Absorption News Letter 1972;11:120-1.

7 Zurlo N, Griffini AM, Colombo G. Determination of lead in urine by atomic absorption spectrophotometry after coprecipitation with thorium. Anal Chim Acta 1969;47: 203-8.

${ }^{8}$ Berlin A, Schaller KH. European standardized method for determination of $\delta$-aminolevulinic acid dehydratase activity in blood. Zeitschrift für Klinische Chemie und Klinische Biochemie 1974;12:389-90.

${ }^{9}$ Schwartz S, Wikoff HM. The relation of erythrocyte coproporphyrin and protoporphyrin to erythropoiesis. J Biol Chem 1952;194:563-73.

${ }^{10}$ Grisler R, Griffini AM. Semimicrometodo e screening test per la determinazione dell'ALA nell'urina. Med Lav 1970; $61: 563-8$.

${ }^{11}$ Alessio L, Castoldi MR, Monelli O, Toffoletto F, Zocchetti C. Indicators of internal dose in current and past exposure to lead. Int Arch Occup Environ Health 1979; 44:127-32.

${ }^{12}$ Alessio L, Bertazzi PA, Monelli O, Toffoletto F. Free erythrocyte protoporphyrin as an indicator of the biological effect of lead in adult males. III Behaviour of free erythrocyte protoporphyrin in workers with past lead exposure. Int Arch Occup Environ Health 1976;38: 77-86.

${ }^{13}$ Waldron HA. The blood lead threshold. Arch Environ Health 1974;29:271-3.

14 Tola S. Erythrocyte $\delta$-amino levulinic acid dehydratase activity after termination of lead exposure. Work Environmental Health 1972;9:66-70.

${ }^{15}$ Haeger-Aronsen B, Abdulla M, Fristedt I. Effect of lead on $\delta$-amino levulinic acid dehydratase activity in red blood cells. II Regeneration of enzyme after cessation of lead exposure. Arch Environ Health 1974;29:150-3.

16 Bonsignore $D$, Ottenga $F$. Differente comportamento dell'ALAD eritrocitaria nel saturnismo florido e cronico sotto trattamento con sale disodico monocalcico di EDTA. Proceedings $X X X V I I I$ Congresso Italiano di Medicina del Lavoro. Milan: Kurtis, 1975:81-4.

${ }^{17}$ Prerovska I, Teisinger J. Excretion of lead and its biological activity several years after termination of exposure. $B r J$ Ind Med 1970;27:352-5. 